\title{
Correlation of disease activity and drug therapy with the autologous mixed lymphocyte reaction in rheumatoid arthritis
}

\author{
SIMONE M CROSS AND R A HAZELTON \\ From the University of Queensland Department of Medicine, Princess Alexandra Hospital, Ipswich Road, \\ Brisbane 4102, Australia
}

SUMMARY The response of peripheral blood lymphocytes (PBL) to autologous synovial fluid lymphocytes (SFL) from patients with rheumatoid arthritis and Reiter's syndrome was investigated in an autologous mixed lymphocyte reaction (AMLR). SFL were found to be pooro responders but strong stimulators of autologous and allogeneic PBL compared with autologous PBL. The plastic-adherent (macrophage) cells from the SFL were found to be highly stimulatory $\frac{}{O}$ to autologous PBL, particularly when the adherent cells were removed from the responding PBL. The stimulation of these PBL non-adherent cells by SFL adherent cells follows two main trends: $\vec{\oplus}$ either no stimulation, or higher stimulation than using unseparated SFL and PBL. Patients in the cor high stimulator group were taking non-steroidal anti-inflammatory drugs while those in the low responder group were taking, in addition, second-line drugs such as D-penicillamine or gold. Autologous serum was found to inhibit the AMLR and this is probably due to drug metabolites in

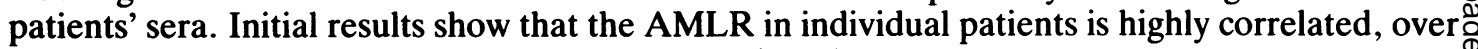
time, with the erythrocyte sedimentation rate (ESR).

Key word: synovial fluid.

The autologous mixed lymphocyte reaction (AMLR) is an in-vitro assay which measures the response of $T$ cells to non- $T$ cell surface membrane antigens, coded for by the HLA-D region. The significance of the AMLR in vivo in normal individuals is uncertain, but there is increasing evidence from in-vitro studies that it plays an important part in the regulation of autoimmune events.

The AMLR demonstrates two fundamental features of immune processes; memory and specificity. ${ }^{1}$ It generates cytotoxic lymphocytes ${ }^{1}$ and perhaps natural killer cells, ${ }^{2}$ and produces suppressor cells ${ }^{3}$ capable of regulating the production of immunoglobulin by $B$ cells $s^{5}$ and the response of $T$ cells to antigen and mitogen. ${ }^{7}$ If the AMLR is a homeostatic regulator of the immune system, then it is possible that any increase in autoreactivity, as in autoimmune disease, may be due to a breakdown of

Accepted for publication 2 October 1984.

Correspondence to Mrs S M Cross, Department of Medicine, Princess Alexandra Hospital, Ipswich Road, Brisbane 4102, Australia. immunoregulation and altered AMLR. This studye suggests such a relationship.

An impairment of the AMLR has been demonstrated in autoimmune disorders such as systemie lupus erythematosus, primary biliary cirrhosis, and Sjögren's syndrome, ${ }^{8}$ and in polymyositis $\&$ dermatomyositis patients, ${ }^{9}$ conditions in which both cellular and humoral immunity are altered. Disturb? ances in immunoregulation have also been detecteff in rheumatoid arthritis (RA) and are believed to bêt due to a lack of suppressor $T$ cell activity ${ }^{8}$ or $T$ celR regression activity. ${ }^{10}$ An increased ratio of helpef suppressor $\mathrm{T}$ cells with a concomitant presence of strongly $\mathrm{DR}^{+}$macrophage-like cells, ${ }^{11}$ which allow autostimulation to persist, have also been described in RA patients. Thus the AMLR may be a usefu $\Gamma$ in-vitro model for the investigation of cellulas interactions important in immunoregulation in $\mathrm{pa}_{\mathbb{\mathrm { D }}}$ tients with RA or other forms of arthritis, such as Reiter's syndrome.

In this study the AMLR has been used to assa仗 the proliferation of peripheral blood lymphocytes 
(PBL) in response to stimulation by autologous synovial fluid lymphocytes (SFL). Previous studies applying the AMLR of PBL to autologous SFL in RA patients have been equivocal about whether the AMLR is stimulated ${ }^{812}{ }^{13}$ or suppressed ${ }^{14}$ and have shown either lack of correlation ${ }^{13}$ or correlation $^{12} 15$ with disease activity. These conflicting results may have been due in part to the use of techniques known to affect cell function. For example, fetal calf serum $^{16}$ and sheep red blood cells (SRBC) used to fractionate cells are stimulatory to $\mathrm{T}$ cells,${ }^{17}$ and the use of hyaluronidase to pretreat synovial fluid samples has previously been found to decrease the response of lymphocytes to mitogens. ${ }^{18}$ By using unfractionated lymphocytes and reducing cell handling an attempt has been made to minimise conditions which may inadvertently alter the immune response under study.

\section{Materials and methods}

PAT IENTS

Twenty-one patients with classical or definite RA (12 females, nine males) and three with Reiter's syndrome were studied. Most patients were receiving non-steroidal anti-inflammatory drugs (NSAID) and some were on second-line drugs as well. Patients on $3 \mathrm{mg}$ of prednisone or more were excluded from the study. Synovial fluid and peripheral blood samples were collected at the time of aspiration and lymphocytes were separated immediately. Two healthy donors acted as a source of control lymphocytes ( $\mathrm{C} 1$ and $\mathrm{C} 2$ ) for each patient's AMLR.

Isolation and growth of lymphocytes were carried out in culture medium RPMI 1640. This medium was supplemented with $5 \%$ pooled human $\mathrm{AB}$ serum during isolation procedures, but to maintain growth either $20 \%$ pooled $\mathrm{AB}$ or autologous serum was used. Lymphocytes from synovial fluid and peripheral blood were isolated by centrifugation on a Ficoll-Hypaque gradient and the cells were not usually fractionated any further before culture. All cells were adjusted to $1.5 \times 10^{9} / 1$ prior to plating into microtitre trays. Where necessary, $T$ and $B$ cells were separated from the mononuclear cells by standard rosetting techniques. ${ }^{19}$ The plastic-adherent cells (predominantly macrophages) were isolated from the SFL and PBL populations by the method of Seitz et al. ${ }^{20}$ and identified by non-specific esterase stain. Primary one-way autologous (AMLR) and allogeneic (aMLR) mixed lymphocyte reactions were performed in 96-well round-bottomed microtitre plates (Disposable Products, Brisbane, Australia) in a chequerboard design with $1.0-1.5 \times 10^{5}$ responder cells and an equal number of mitomycin- $C$ treated $\left(40 \mathrm{mg} / \mathrm{l}\right.$ cells for 20 minutes at $37^{\circ} \mathrm{C}$ ) stimulator cells in a final volume of $200 \mu \mathrm{l} /$ well. All cultures were grown at $37^{\circ} \mathrm{C}, 5 \% \mathrm{CO}_{2}$ in air for six days. Phytohaemagglutinin (PHA-P, Difco, Detroit, Michigan) was added to each responder cell $(10 \mathrm{mg} / \mathrm{l})$ alone, 72 hours prior to harvest. Proliferative responses were measured by adding $1 \mu \mathrm{Ci} /$ well of ${ }^{3} \mathrm{H}$-thymidine (New England Nuclear, Boston, Mass.) for the final 18-20 hours of culture. The cells were harvested with a Skatron multisample harvester, and the incorporation of ${ }^{3} \mathrm{H}$-thymidine determined by standard liquid scintillation counting techniques. Results are expressed as mean disintegrations per minute $(\mathrm{dpm})$ in

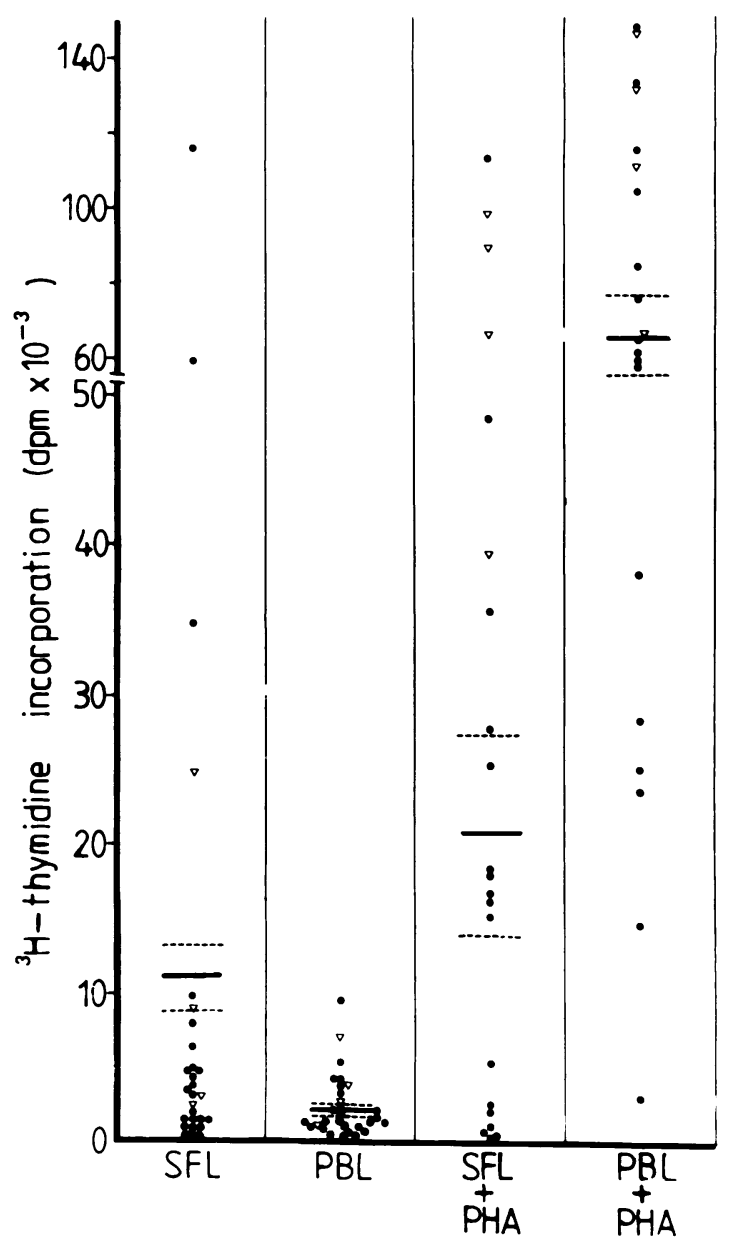

Fig. 1 Incorporation of ${ }^{3} \mathrm{H}$-thymidine into $S F L, P B L$, $P H A$-treated SFL and PBL of RA (O) and Reiter's disease patients $(\nabla)$. Shown are the mean and SEM. The mean incorporation into $S F L$ was $11000 \mathrm{dpm} ; P B L, 2228 \mathrm{dpm}$, SFL + PHA, $20500 \mathrm{dpm}$, and PBL + PHA, $64000 \mathrm{dpm}$, were significantly different $(p<0 \cdot 01)$. Each point represents the mean of quadruplicate cultures. 
quadruplicate cultures minus the background dpm in responder cells when cultured alone. All comparisons were analysed by either a paired or an unpaired Student's $t$ test.

\section{Results}

Cultures revealed that the optimal ratio of respon-

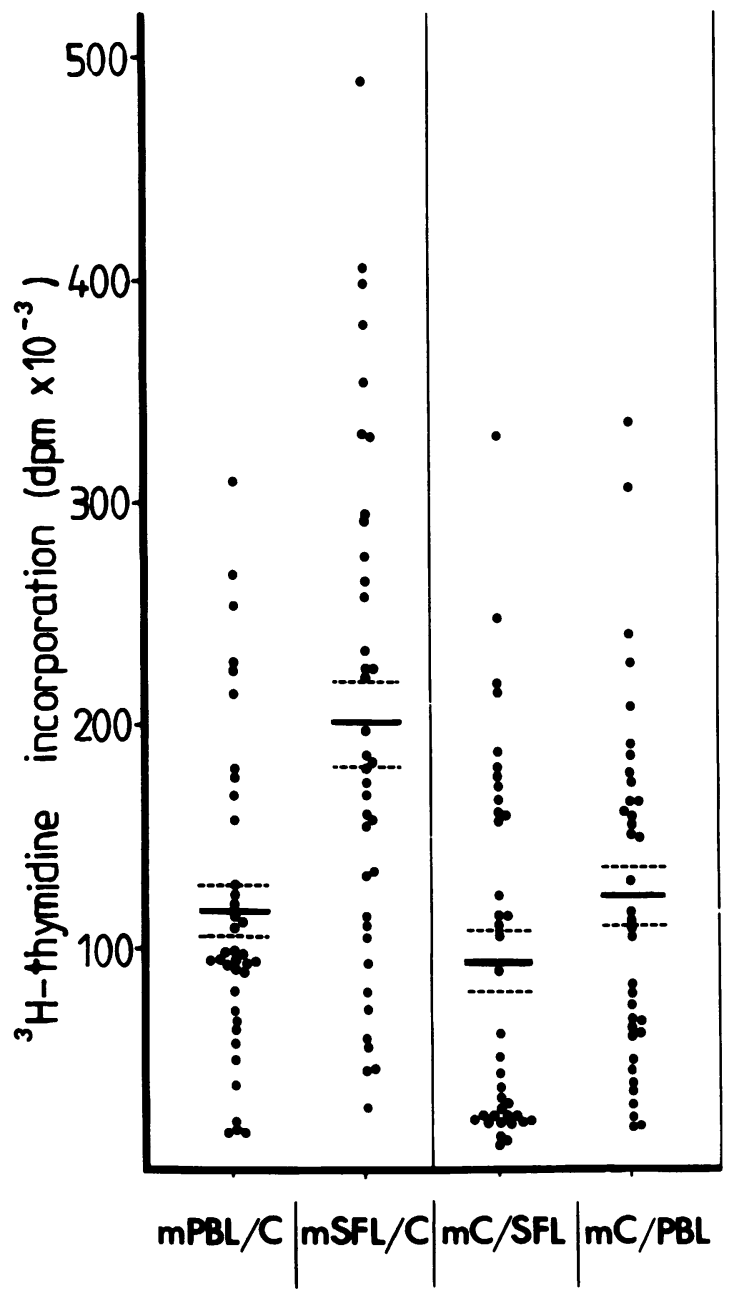

Fig. 2 Allogeneic stimulation and response of SFL and $P B L$ from $R A$ patients. Results are shown as the mean $\pm S E M$ of ${ }^{3} \mathrm{H}$-thymidine incorporation. Stimulation of control cells (C) by mitomycin-C treated SFL ( $m S F L$ ) gave $200100 \mathrm{dpm}$, significantly higher than mitomycin-C treated PBL ( $\mathrm{mPBL} / \mathrm{C}$ ) which gave $116624 \mathrm{dpm}$ in a paired test $(p<0.001)$. The response of SFL ( $m$ C/SFL) was 93500 dpm, significantly less than mC/PBL which gave 122572 dpm $(p<0.005)$. Each point is the mean of quadruplicate cultures. der to stimulator cells was $1: 1$ and that the optima므. response occurred on day 6 in both the AMLR and? aMLR.

SFL were found to be good stimulators in theo AMLR but poor responders to PHA and allogeneico or autologous stimulation. The following results confirmed that the SFL were already activated $\mathbb{\Phi}$

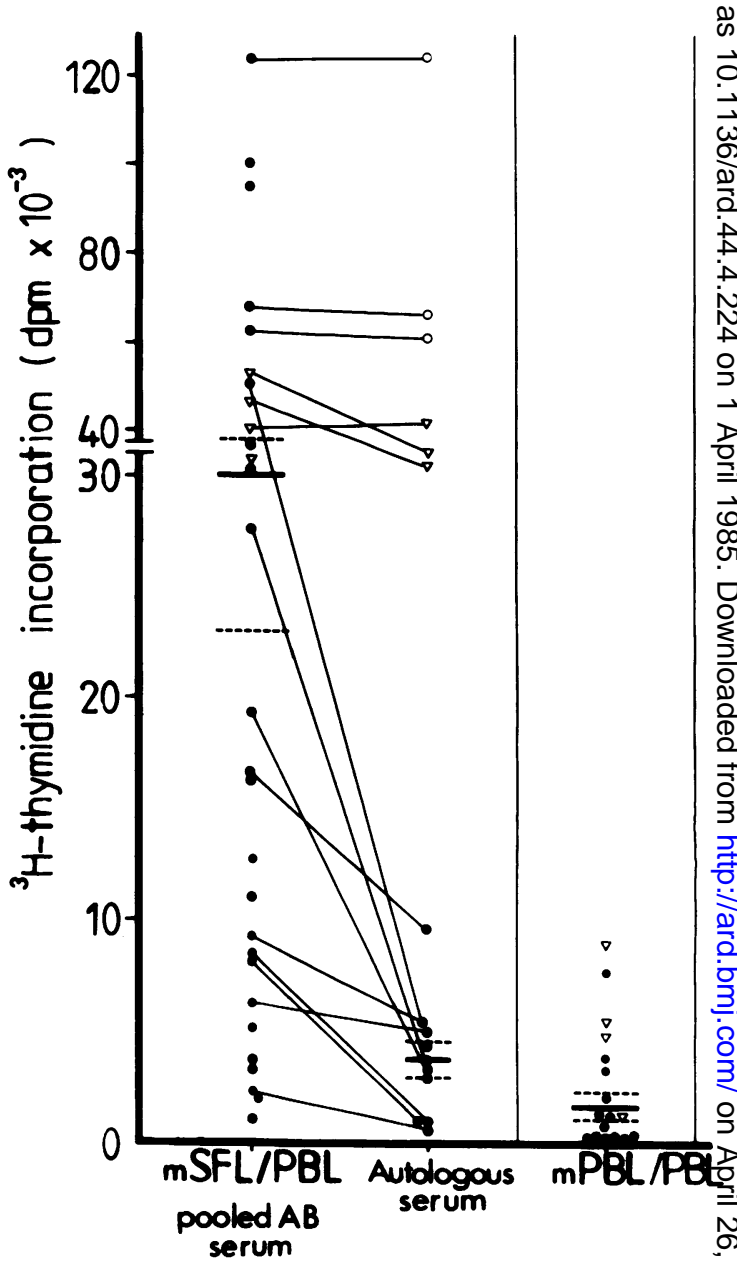

Fig. 3 The AMLR (mSFL/PBL) of RA (O) and Reiter's disease patients $(\nabla)$ in pooled $A B$, and autologous serum is $\omega$ compared with the other autologous combination $M P B L / P B L . R A$ and Reiter's disease patients who were not taking medication or who had medication withdrawn 48 hours prior to assay, are represented by open symbols $(O, \stackrel{D}{4}$ $\nabla)$. Shown are the mean (dpm) $\pm S E M$, and each point is the mean of quadruplicate cultures. The mean incorporation for the AMLR of RA patients is $30000 \mathrm{dpm}$ (Reiter's disease patients $43500 \mathrm{dpm}$ in pooled $A B$ serum, but only $3700 \mathrm{dpm}$ in the autologous serum of patients on drugs $(p<0.05)$. The AMLR is significantly larger $(p<0.01)$ than mPBL/PBL (1500 dpm). 
(1) the increased incorporation of ${ }^{3} \mathrm{H}$-thymidine into resting SFL compared with autologous PBL was some three times greater on average (Fig. 1); (2) PHA stimulation of SFL was significantly lower compared with autologous PBL $(\mathrm{p}<0.01)$; (3) SFL as stimulators in the aMLR induced a significantly larger response than autologous PBL $(p<0.001)$ (Fig. 2); and (4) SFL responded less than autologous PBL $(\mathrm{p}<0.005)$ to allogeneic cells (Fig. 2).

In pooled $\mathrm{AB}$ serum (Fig. 3) the only cell combination that showed significant autologous stimulation was with mitomycin-C treated SFL as stimulator and PBL as responder (mSFL/PBL). The mean response of this AMLR was $30000 \mathrm{dpm}$ for patients with RA and $43500 \mathrm{dpm}$ for patients with Reiter's disease. This response was statistically larger than that for other autologous combinations such as $\mathrm{mPBL} / \mathrm{PBL}$, $\mathrm{mSFL} / \mathrm{SFLm}$ and $\mathrm{mC} / \mathrm{C}$ (RA, $\mathrm{p}<0.01$; Reiter's disease, $\mathrm{p}<0.001)$. The patients with Reiter's disease showed less variation in their AMLR response than RA patients.

Cultures with sonicated SFL revealed negligible stimulation (mean incorporation $900 \mathrm{dpm}$ ) compared with the mean AMLR (30000 dpm).

In nine out of 12 RA patients the addition of autologous serum severely decreased the AMLR to control levels, compared with pooled $A B$ serum $(p<0 \cdot 05)$. This autologous serum was also found to suppress the response of lymphocytes to PHA stimulation. However, as shown in Fig. 3, three patients with RA and three with Reiter's disease who had not taken any medication or who had ceased medication at least $48 \mathrm{~h}$ prior to assay had an AMLR which was relatively unchanged by incubation in autologous serum.

Removal of the adherent cells from the stimulating population ( $\mathrm{mSFL}$ ) in the AMLR caused a significant decrease in thymidine incorporation in eight of the 12 cultures of RA patients but was not significantly affected in four of the RA patients (Table 1). In these four cultures stimulation in the AMLR resided in the non-adherent fraction of SFL. The mean incorporation of these mSFL nonadherent/PBL mixtures was $14829 \mathrm{dpm}$, about half of the unfractionated $\mathrm{mSFL} / \mathrm{PBL}$ combination (27 $706 \mathrm{dpm})$. Adherent cells removed from the responder PBL population when stimulated by unfractionated mSFL cells in the AMLR resulted in either a decreased, increased, or indifferent response (Table 1). In two of the 11 cultures from patients with RA there was a significant decrease in the AMLR response, while in six patients removal of the macrophages from the responding PBL population had no effect; but in three cultures there was a greatly increased response, far larger than the initial AMLR. The stimulation of PBL by PBL (adherent) cells was negligible (Table 2). In seven of the 10 RA patients the mean stimulation of PBL by autologous SFL (adherent) was $10390 \mathrm{dpm}, 10$ times larger than PBL (adherent) cells, but significantly less than with unfractionated $\mathrm{mSFL}$. In three cases the mSFL (adherent) cells were not significantly different, compared with $\mathrm{mSFL}$, in their stimulating capacity (Table 2 ).

Table 1 Effects of removal of the plastic-adherent cells on the AMLR

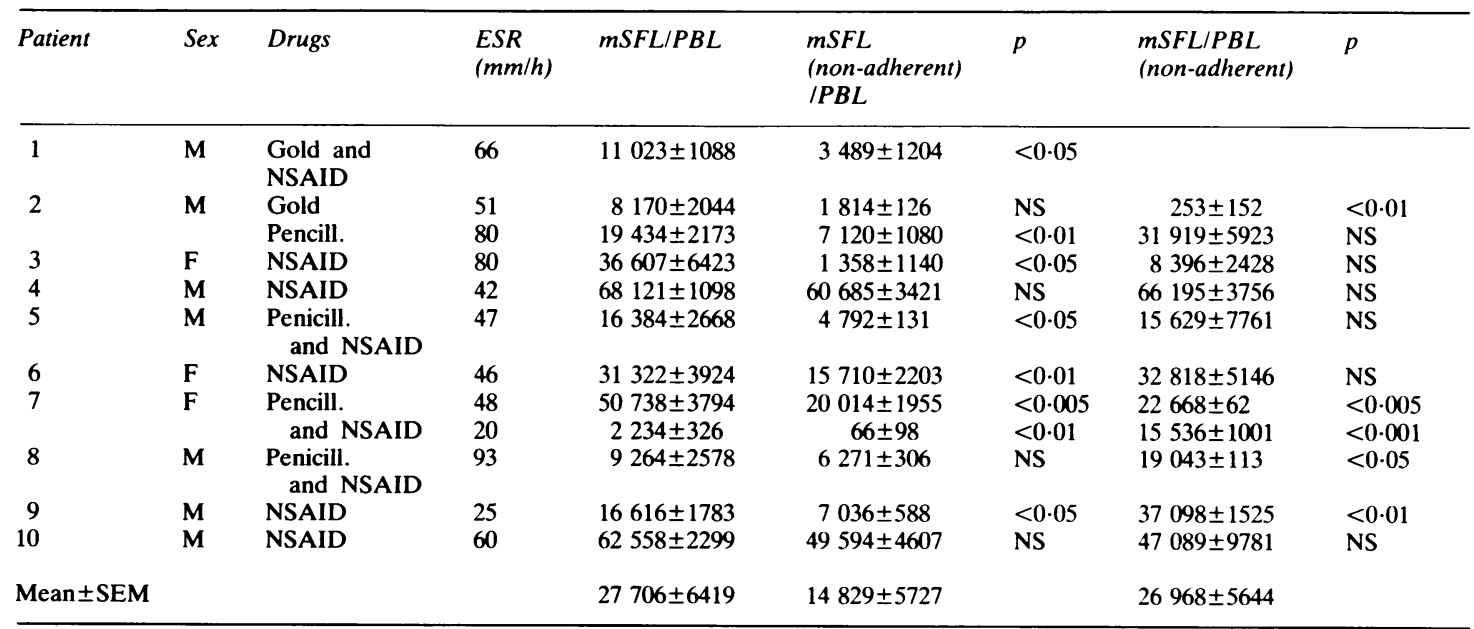

Results are the mean (dpm) of quadruplicate cultures, and results of the non-adherent cells are compared with each patient's AMLR using a Student's paired $t$ test.

NS $=$ Not significant .

Penicill. $=$ Penicillamine. NSAID = Non-steroidal anti-inflammatory drugs. Patients 10 in Tables 1 and 2 are different subjects 


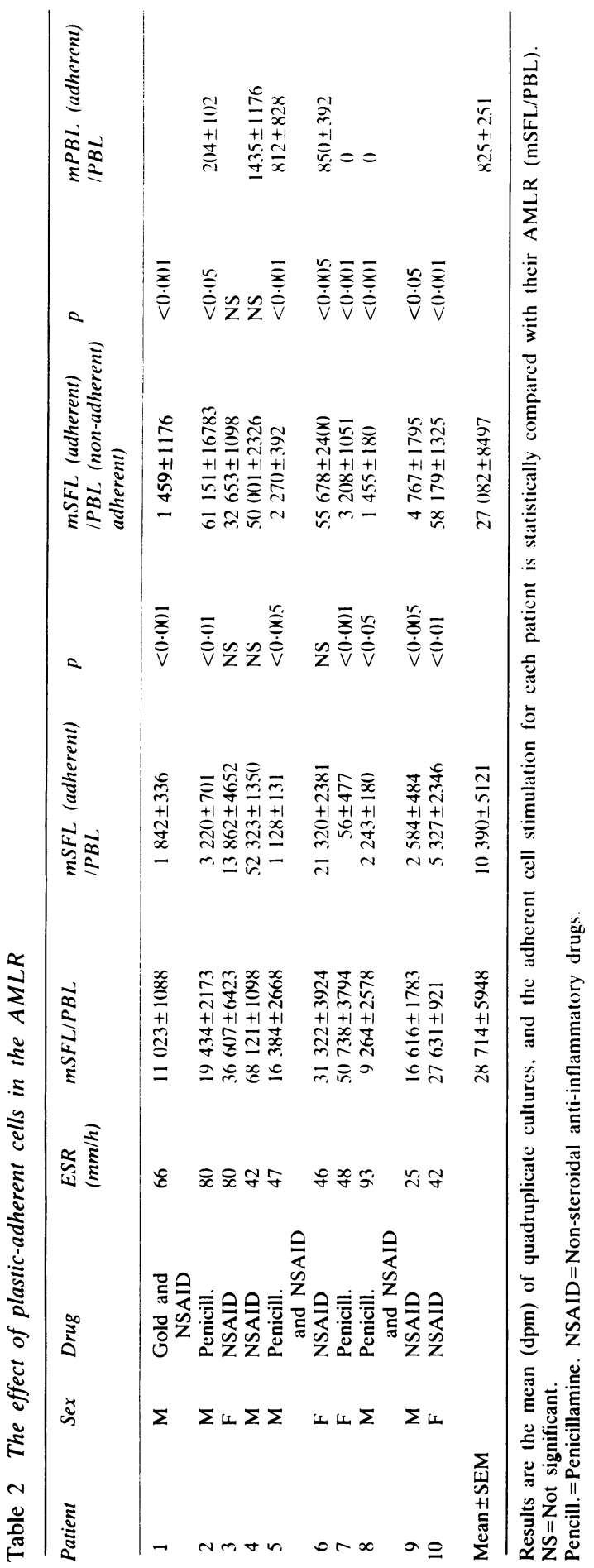

Since removal of the macrophages from the $\frac{\text { 으. }}{\text {. }}$ responding population caused an increased AMLR $\stackrel{\vec{\Rightarrow}}{\Rightarrow}$ in some patients, mSFL (adherent) cells were $\stackrel{9}{\rightarrow}$ incubated with PBL from which the adherent cells 0 had been removed (Fig. 4). In five patients this AMLR, mSFL (adherent)/PBL (non-adherent) was $\frac{\bar{\rho}}{\partial}$ significantly reduced (mean $2600 \mathrm{dpm}$ ) as compared $\stackrel{\mathbb{\Phi}}{\square}$ with a normal AMLR response $(\mathrm{mC} / \mathrm{C})$. In two cases (RA) the AMLR was unchanged; but in three $\vec{\circ}$

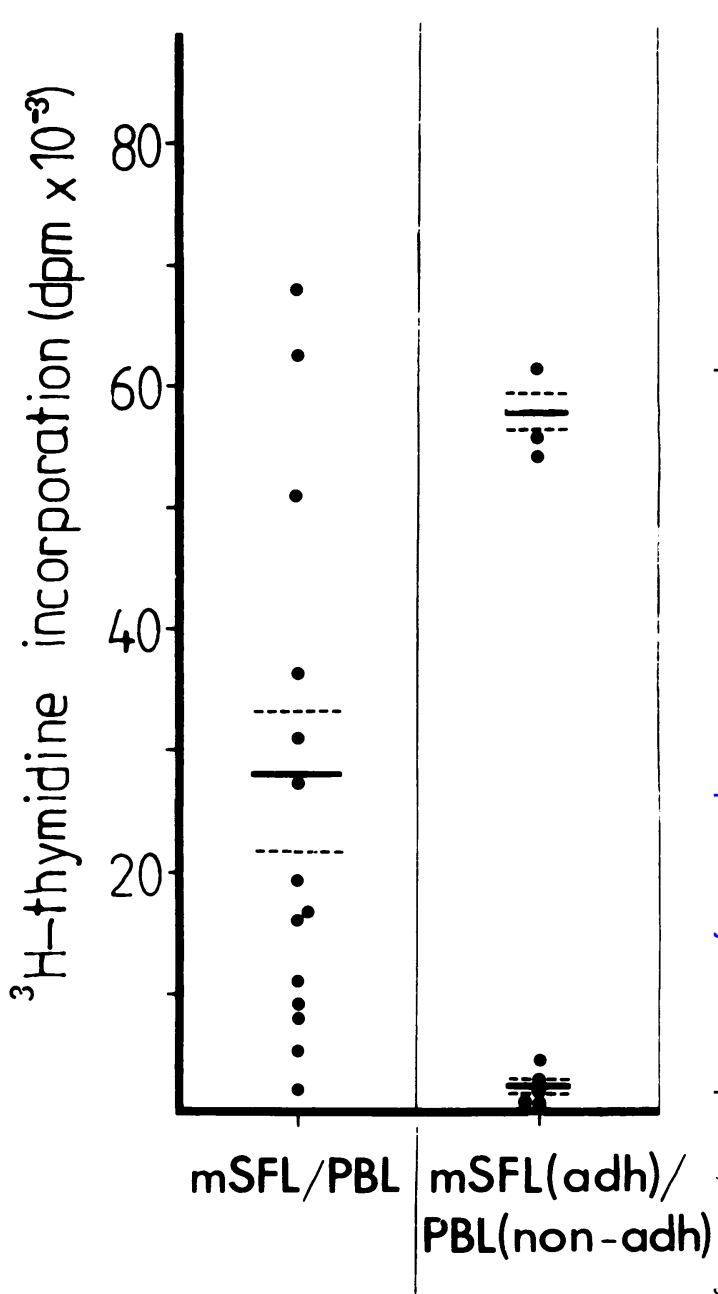

Fig. $4{ }^{3} H$-Thymidine incorporation in the $A M L R$ ( $m S F L / P B L)$ and stimulation by the plastic-adherent cells of the SFL, $\mathrm{mSFL}($ adh), in the AMLR. Shown is the mean $($ dpm $) \pm S E M$ and all points are the mean of quadruplicate cultures. The mSFL(adh) are incubated with $P B L$ (non-adh) cells. The mean AMLR in these RA patients is $27700 \mathrm{dpm}$. The mSFL(adh)/PBL(non-adh) response is divided into high responders (58 $300 \mathrm{dpm})$ and low responders $(2600 \mathrm{dpm}$ ) which recently showed an increased ordecreased ESR (of $>20 \mathrm{~mm} / \mathrm{h}$ ) respectively. 


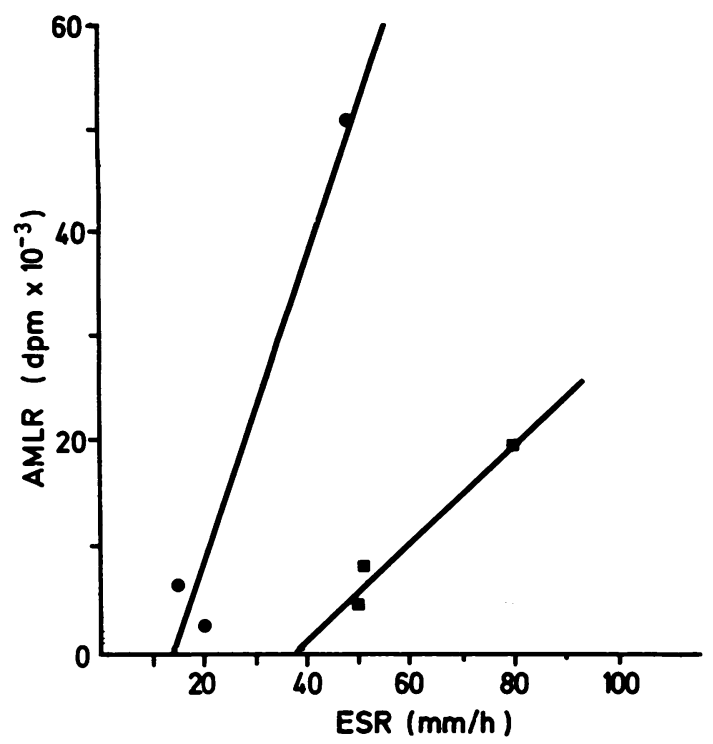

Fig. 5 Correlation of the AMLR with ESR in RA patient 7 (O), $r=0.98, p<0.05$ and patient 2 ( $), r=0.97, p<0.05$ on threeseparate occasions.

cases (RA) the AMLR was markedly increased (mean $58300 \mathrm{dpm}$ ).

The patients were now observed to form two distinct groups where the AMLR was altered with removal of PBL macrophages. Those patients in the upper response group all had very active disease and a recent increase in their ESR (greater than 20 $\mathrm{mm} / \mathrm{h}$ ). All three patients were taking NSAID and one patient took penicillamine. The lower group of patients were on gold or penicillamine, and only one patient out of five was taking NSAID alone. Their low AMLR correlated with a recent decrease in ESR.

Though the overall data showed no correlation of the AMLR with ESR, serum rheumatoid factor, or synovial fluid C-reactive protein at the time of assay, in two cases sequential studies revealed a significant correlation of ESR with the AMLR (Fig. 5).

\section{Discussion}

In keeping with other studies employing surface markers and immunohistochemical stains of lymphocyte activation ${ }^{21} 22$ in RA the SFL in the present study were found to be significantly more activated than autologous PBL in both RA and Reiter's disease patients. The origin of the activated SFL in RA is uncertain, though it has been suggested that they arise from the superficial layer of synovium. ${ }^{23}$

In the AMLR the SFL were potent stimulators of autologous PBL. The reason for this may be that the SFL and PBL express some class II region disparity due to altered or previously unexpressed antigens. It has been found that for the production of immunoglobulin-producing cells (via induction of helper T cells), class II region disparity is essential in the primary MLR. ${ }^{24}$ The cause of this disparity may be explained by the modified-self theory, ${ }^{25}$ in which autostimulation can occur by the presentation of modified-self antigens of cross-reacting microbial antigens with class II products, by antigen presenting cells. The very low levels of stimulation by sonicated SFL in the AMLR suggest that an active cell product is required, either soluble or membrane bound. The addition of IL-2 to activated lymphocytes is known to lead to clonal expansion, ${ }^{26}$ though IL-2 production is depressed in RA. ${ }^{27}$

Studies on tissue sections ${ }^{1128}$ suggest that the presence of strongly HLA-DR ${ }^{+}$macrophage-like cells are the cause of stimulation of autologous synovial $T$ cells and these are supported by studies of RA SFL (adherent) in this report. Removal of the SFL (adherent) cells greatly reduced the AMLR in RA patients, indicating that these synovial macrophages were stimulatory. The SFL (non-adherent) cells were also stimulatory but not to the same extent as unseparated SFL. The SFL (adherent) cells alone were also capable of inducing significant stimulation when incubated with autologous PBL. When the mean value for the SFL (adherent) cell stimulation was added to that of SFL (non-adherent) cells, the combined stimulation was slightly less than that of unfractionated SFL. This implies a synergistic relationship between synovial fluid lymphocyte and macrophage cells. This communication between cell types involved in immunoregulatory responses would be expected to occur in the AMLR, creating either an increased or decreased response above that of either cell type alone. A previous study found that macrophages are capable of either stimulation or suppression of immune responses. ${ }^{29}$ This is confirmed in part in the current study, which suggests that SFL (adherent) cells are stimulatory, while PBL (adherent) cells are not and in fact may be inhibitory in the AMLR. Removal of adherent cells from the PBL population greatly increased the response of some RA patients' PBL to either unfractionated SFL (Table 1) or SFL (adherent) cells. The incubation of mSFL (adherent) with PBL non-adherent cells resulted in some RA patients in an AMLR much larger than the combination $\mathrm{mSFL} / \mathrm{PBL}$. This implies that the PBL (adherent) cells recognise the SFL as foreign and are either producing an inhibitory factor, such as prostaglandin $E_{2},{ }^{20} 3031$ or are inducing suppressor $\mathrm{T}$ cell activity in the PBL population. 
The division of the response of non-adherent PBL to SFL (adherent) cells into high and low responders may be due to drug therapy. Second-line drugs such as gold, D-penicillamine, and steroids have been shown to affect the AMLR and are proposed to affect the antigen-presenting function of macrophages by binding to HLA-DR determinants. ${ }^{32} 33$ These drugs are therefore potentially capable of decreasing the AMLR. This response to mSFL (adherent) cells also seems to be correlated with relative (recent) changes in ESR.

The findings of a possible correlation between the AMLR and the relative changes in the ESR may explain the lack of correlation between absolute values of the ESR and the AMLR. The AMLR was found to be highly correlated with ESR in two patients with RA, over time, and hence may be a useful predictor of subsequent disease activity, though a prospective study would be required to confirm this. ESR and other laboratory indices such as C-reactive protein are indirect measures of inflammation and probably not of RA disease activity per se. However, an increased AMLR would be expected if inflammation of the joint increased because of the sequestration of lymphocytes and neutrophils to the inflammatory site. Previous investigators have differed over whether the AMLR is correlated with disease activity, but none have conducted longitudinal studies of patients. The study of patients not on any drug treatment, or those on first-line drugs who have not taken medication for at least 48 hours prior to assay, appeared to increase the correlation of the AMLR with the ESR.

Since previous investigators ${ }^{14} \quad 34-37$ have found that autologous serum suppresses the AMLR, possibly because of the proved effect of drugs and their metabolites on the AMLR, it was decided to incubate cells in human pooled AB serum. AMLR patients with Reiter's syndrome were not affected significantly by the addition of autologous serum. Often these patients had only just commenced NSAID therapy, and perhaps this explains the lack of suppression of the AMLR by their serum. This may also explain the much reduced variability of their AMLR compared with that of RA patients. Because the AMLR of patients not on drug treatment was unaffected by autologous serum, the inhibitor in autologous serum is thought not to be an HLA-restricted suppressor factor.

In conclusion because of the demonstration of the AMLR and its correlation with an index of disease activity, this provides evidence in support of the AMLR as an in-vivo phenomenon important in the pathogenesis of RA. This study also suggests that the AMLR may be a useful index and predictor of future disease activity. The AMLR may provide a useful in-vitro model for the screening of various? chemotherapeutic agents in RA.

This research was funded in part by the Arthritis Foundation of Australia (Queensland) and the National Health and Medical Research Council of Australia.

\section{References}

1 Weksler M E, Birnbaum G. Lymphocyte transformation $\overrightarrow{0}$ induced by autologous cells. Stimulation by cultured lymphoblast line. J Clin Invest 1972; 51: 3124-32.

2 Silver R M, Redelman D, Zvaifler N J, Naides S. Studies of rheumatoid synovial fluid lymphocytes. I. Evidence for acti- @ِ vated natural killer-(NK) like cells. J Immunol 1982; 128: $\overline{\mathrm{C}}$ 1758-63.

3 Smith J B, Knowlton K P. Activation of suppressor T cells in human autologous immune lymphocyte culture. I Immunol 1979; 123: 419-22.

4 Goeken N E, Melton Z J. Immunoregulatory activity of T-cell subsets activated in human mixed lymphocyte reaction. Hum Immunol 1983; 6: 79-90.

5 Hausman P B, Stobo J D. Specificity and function of a human $D$ autologous reactive T cell. J Exp Med 1979; 149: 1537.

6 Gatenby P A, Kotzin B L, Engleman E G. Induction of immunoglobin secreting cells in the human autologous mixed $\overrightarrow{0}$ leukocyte reaction: regulation by helper and suppressor lymphocyte subsets defined with monoclonal antibodies. $J$ Immunol 1981; 127: 2130-5.

7 Sakane T, Greene I. Specificity and suppressor function of human $T$ cells responsive to autologous non-T cells. $J$ Immunol 1979; 123: 538-89.

8 Førre $\emptyset$, Egeland T, Dobloug J H, Kvien T K, Natvig J B. 气ิ Autologous mixed lymphocyte reactions in patients with $\mathbb{D}$ rheumatoid arthritis and juvenile RA: both non- $T$ cells and in-vivo-activated $\mathrm{T}$ cells can act as stimulator cells. Scand $J \overrightarrow{\mathrm{O}}$ Immunol 1982; 16: 173-9.

9 Ransohoff $\mathrm{R} \mathrm{M}$, Dustdor $\mathrm{M} \mathrm{H}$. Impaired autologous mixed lymphocyte reaction with normal concanavalin A-induced $\bar{\nabla}$ suppression in adult polymyositis/dermatomyositis. Clin Exp Immunol 1983; 53: 67-75.

10 Moss D J, Klestov A, Burrows S, Kane R G. A comparison of Epstein-Barr virus-specific $T$-cell immunity in rheumatoid arthritis and osteoarthritis patients. Aust J Exp Biol Med Sci 1983; 61: $509-16$.

11 Janossy G, Duke O, Poulter L W, Panayi G, Bofill M, Goldstein G. Rheumatoid arthritis: a disease of T-lymphocyte/ macrophage immunoregulation. Lancet 1981; ii: 839-42.

12 Okamoto R. Blastogenesis of peripheral blood lymphocytes by $D$ autologous synovial fluid lymphocytes and synovial fluid from 음 patients with rheumatoid arthritis. Jap J Orthop Surg 1979; 53: 441-55.

13 Beck P, Burmester G R, Ledwoch A, Urban C, Kalden J R. Autologous and allogeneic MLC-reactivity in patients with $\mathrm{N}$ rheumatoid arthritis. J Clin lab Immunol 1981; 6: 27-33.

14 Keystone E C, Gladman D D, Urowitz M B, et al. Mixed leukocyte reaction in rheumatoid arthritis. Arthritis Rheum $<$ 1976; 19: 532-8.

15 Sauvezie B, Miyasaka N, Charron D, et al. An increase in $\frac{C}{\mathscr{D}}$ peripheral blood Ia-positive $T$ cells in Sjögren's syndrome correlates with a decrease in the autologous mixed lymphocyte responses. Clin Exp Immunol 1982; 49: 50-8.

16 Misko I S, Pope J H, Kane R G, Bashir H, Doran T. Evidence for the involvement of HLA-DR antigens in restricted cyto- $\Omega$ toxicity by fetal calf serum-specific human $\mathrm{T}$ cells. Hum $\mathbb{D}$ Immunol 1982; 5: 183-97.

17 Canonica G W, Kabelitz D, Sjöberg O, Aigrain Y, Nigzell H. Density distribution profiles of cells: $\mathrm{Tm}, \mathrm{Tg}$ and $\mathrm{Ta}$ cells and $\Omega$ 
response patterns in autologous vs. allogeneic MLRs. Scand J Immunol 1982; 16: 243-8.

18 Crout J E, McDuffie F C, Ritts R E Jr. Induction of peripheral blood lymphocyte transformation by autologous synovial fluid lymphocytes and synovial fluid. Arthritis Rheum 1976; 19: 523-32.

19 Saxon A, Feldhaus J, Robins R A. Single step separation of human $\mathrm{T}$ and $\mathrm{B}$ cells using AET treated sheep red cells. $J$ Immunol Methods 1976; 12: 285.

20 Seitz M, Deimann W, Gram N, Hunstein W, Gemsa D. Characterization of blood mononuclear cells of rheumatoid arthritis patients. I. Depressed lymphocyte proliferation and enhanced prostanoid release from monocytes. Clin Immunol Immunopathol 1982; 25: 405-16.

21 deVries E, Meijer C J L M, Lafeber G J M, Cnossen J, Cats A. Lymphocyte subpopulations in rheumatoid arthritis. An immunological, enzyme histochemical and morphological study. Rheumatol Int 1984; 4: 91-4.

22 Duclos M, Zeidler H, Liman W, Pichler W J, Rieber P, Peter H $H$. Characterization of blood and synovial fluid lymphocytes from patients with rheumatoid arthritis and other joint diseases by monoclonal antibodies (OKT series) and acid alphanaphthyl esterase staining. Rheumatol Int 1982; 2: 75-82.

23 Koch B, Locher P, Burmester G R, Mohr W, Kalden J R. The tissue architecture of synovial membranes in inflammatory and non-inflammatory joint diseases. II. The localization of mononuclear cells as detected by monoclonal antibodies directed against T-lymphocyte subsets and natural killer cells. Rheumatol Int 1984; 4: 79-85.

24 Garovoy M R, Reddish M A, Abbas A K. Generation of immunoglobulin secreting cells in mixed lymphocyte culture. Hum Immunol 1981; 3: 31-44.

25 Scott D W, Darrow T L, Grouix B, Wilson L A. Recognition and regulation by modified self. In: Battisto $J$ R, Claman $H ~ N$, Scott D W, eds. Immunological tolerance to self. New York: New York Academy of Sciences, 1982; 392: 1-22.

26 Solbach W, Barth S, Röllinghoff $M$, Wagner $\mathbf{H}$. Interactions of human $T$ cell subsets during the induction of cytotoxic $T$ lymphocytes: the role of interleukins. Clin Exp Immunol 1982: 49: 167-75.

27 Alcocer-Varela J, Laffon A, Alarcon-Segovia D. Differences in the production of and/or the response to interleukin- 2 by $T$ lymphocytes from patients with various connective tissue diseases. Rheumatol Int 1984; 4: 39-44.

28 Duke O, Panayi G S, Janossy G, Poulter L W. An immunohistological analysis of lymphocyte subpopulations and their microenvironment in the synovial membranes of patients with rheumatoid arthritis using monoclonal antibodies. Clin Exp Immunol 1982; 99: 22-30.

29 Smolen J S, Chused T M, Novotny E A, Steinberg A D. The human autologous mixed lymphocyte reaction. III. Immune circuits. J Immunol 1982; 129: 1050.

30 Skoldstam L, Zoschke D, Messner R. Contrasting effects of prostaglandin $\mathrm{E}_{2}$ and indomethacin in modulating $\mathrm{Cn} A$ induced human lymphocyte proliferation and suppressor cell development. Clin Immunol Immunopathol 1982; 25: 32-42.

31 Snyder D S, Beller D I, Unanue E R. Prostaglandins modulate macrophage Ia expression. Nature 1982; 299: 163-5.

32 Hirschberg H, Braathen L R. Thorsby E. Antigen presentation by vascular endothelial cells and epidermal langerhans cells: The role of HLA-DR. Immunol Rev 1982; 66: 57-77.

33 Watanabe H, Dawkins R L, Garlepp M J. D-penicillamineimmunogenetics of effects and side effects. In: Dawkins $R L$, Christiansen F T, Zilko P J, eds. Immunogenetics in rheumatology. Amsterdam: Excerpta Medica, 1982: 291-6.

34 Forbes I J, Smith J L. Effects of anti-inflammatory drugs on lymphocytes. Lancet 1967; ii: 334-7.

35 Fauci A S, Dale D C. The effect of in vivo hydrocortisone on subpopulations of human lymphocytes. J Clin Invest 1974; 53: $240-6$.

36 Hepburn B, McDuffie F C, Ritts R E Jr. Impaired blastogenic response of lymphocytes from synovial fluid and peripheral blood of patients with rheumatoid arthritis. J Rheumatol 1976; 3: $118-23$.

37 Opelz G, Terasaki P I, Hirata A A. Suppression of lymphocyte transformation by aspirin. Lancet 1973; ii: $478-80$. 